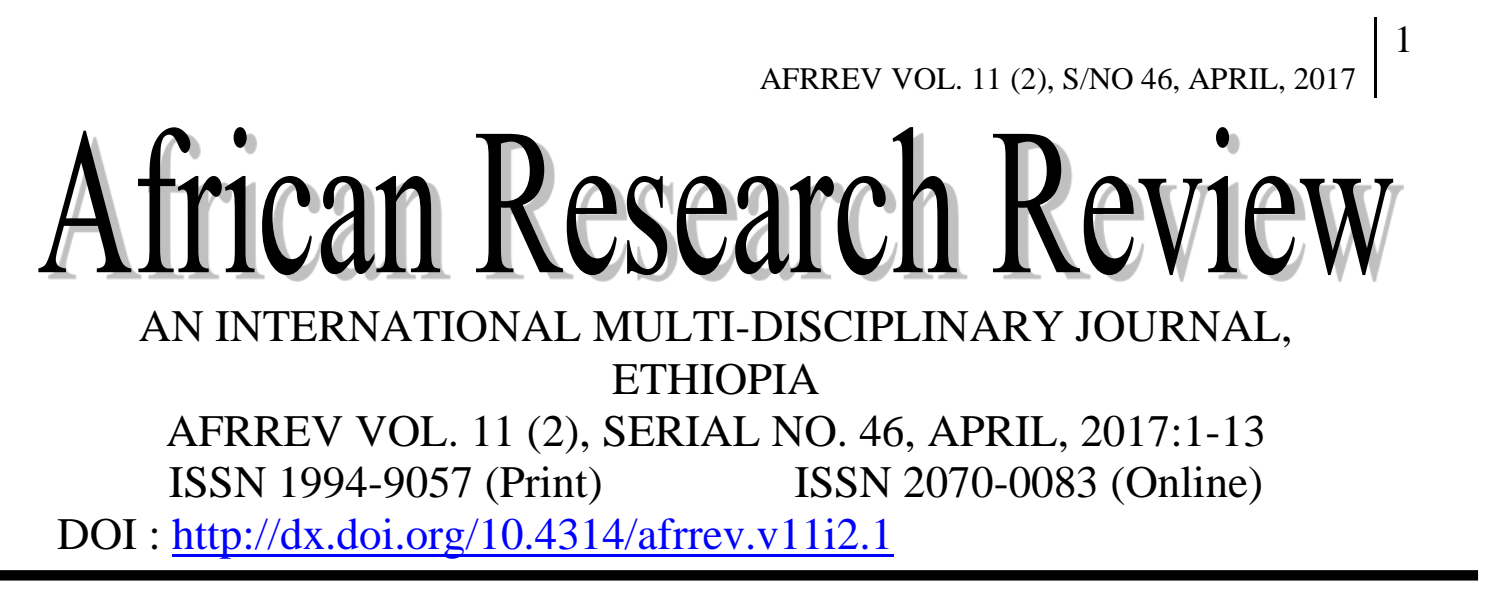

\title{
Road Crashes in Addis Ababa, Ethiopia: Empirical Findings between the Years 2010 and 2014
}

\author{
Tariku Ayana Abdi \\ Faculty of Psychology \\ University of Valencia \\ Valencia, Spain \\ E-mail: tarikuayanaabdi@gmail.com
}

\section{Belay Hagos Hailu}

Institute of Educational Research

Addis Ababa University,

Addis Ababa, Ethiopia

\section{Tamirie Andualem Adal}

School of Psychology

Addis Ababa University

Addis Ababa, Ethiopia

van Gelder, Pieter H. A. J. M.

Safety and Security Institute,

Delft University of Technology, Delft, Netherlands

Copyright $($ C) International Association of African Researchers and Reviewers, 2006-2017: 
AFRREV VOL. 11 (2), S/NO 46, APRIL, 2017

\author{
Marjan P. Hagenzieker \\ Civil Engineering and Geosciences Department (Transport \& Planning) \\ Delft University of Technology \\ Delft, The Netherlands
}

Claus-Christian Carbon

Department of General Psychology and Methodology

University of Bamberg, Bamberg, Germany

Bamberg Graduate School of Affective and Cognitive Sciences

(BAGrACS)

Bamberg, Germany

\begin{abstract}
Ethiopia has a high road crash rate in the world. Among the crashes, more than $60 \%$ occur in the capital city, Addis Ababa. The main aim of this research was to inform policymakers and researchers about the current situations of road crashes in the city to tackle the current unacceptable costs of the road crashes. We analyzed road crash data between the years 2010 and 2014. The results showed 14,263 persons sustained different levels of injuries in which 1,911 were fatal whereas the rest were serious and minor injuries. Majority of the fatal (79\%) and serious (76\%) injuries were males, and pedestrians $(87 \%)$. Most of these crashes were due to the drivers' not yielding right of way to pedestrians. On the other hand, an estimated 19 million US dollars cost of property damage was due to the drivers not yielding right of way to other vehicles. Generally, among other risk factors we assessed including road conditions and asphalt pavement, drivers' not yielding right of way to pedestrians and not yielding right of way to other vehicles were the leading risk factors for road crashes in the city.
\end{abstract}

Key Words: Road Crash; Fatalities; Serious Injuries; Minor Injuries; Safety

\title{
Introduction
}

Road crashes nowadays are becoming a global public health concern, especially in African countries. According to a World Health Organization report in 2015, Ethiopia is one of the 50 countries with the deadliest roads in the world (The Economist, 2015). According to the report, road crashes kill more people in African countries like Ethiopia, Kenya and most other sub-Saharan countries than malaria does. Earlier studies on road crashes forecasted road traffic fatalities to be the second leading cause of disability-adjusted life-years lost (accounting for more than $85 \%$ of all fatalities and $90 \%$ of disability-adjusted life-years lost) in developing countries - most of which are

Copyright (C) International Association of African Researchers and Reviewers, 2006-2017: www.afrevjo.net.

Indexed African Journals Online: www.ajol.info 
African countries - by the year 2020 (Kopits \& Cropper, 2003; Nantulya \& Reich, 2004; Lagarde, 2007; Hassen, Godesso, Abebe, \& Girma, 2011).

Whereas international studies have shown that road crashes in developed countries have been decreasing in the past decades, in developing countries the opposite trend has become apparent (Kopits \& Cropper, 2003). For instance, in Germany, road crashes fell by $82.4 \%$ between the years 1974 and 2014 (Statistisches Bundesamt, 2016); in the Netherlands, the crashes fell by 82.5\% between the years 1970 and 2014 (SWOV, 2015); in Hong Kong and Canada road fatalities per person in fell by $60 \%$ whereas they increased in developing countries like Botswana and Cambodia by $200 \%$ between the years 1975 and 1998 (Kopits \& Cropper, 2003).

Considering the trend of road crashes in Addis Ababa, Ethiopia, completely the opposite is apparent. Studies revealed that Ethiopia is reported to be the country with deadliest roads in the world, indicating a road crash fatality rate of at least 114 per 10,000 vehicles per year, compared to only 10 in the UK and Ireland and 60 across 39 sub-Saharan African countries. Furthermore, the number of people injured or killed in one crash in Ethiopia is about 30 times higher than in the US (e.g., Fessaha \& Sileshi, 2014; Tesema, Abraham, \& Grosa, 2005). According to their review, Addis AbabaEthiopia's capital city - shares $60 \%$ out of the total number of vehicles in the country while its population is only about $3.2 \%$ of the total population for the country (e.g., United Nations data as of 2016, retrieved from: http://data.un.org/CountryProfile.aspx?crName=Ethiopia). However, sadly, contributes to about $60 \%$ of all road crashes occurring in the country. The United Nations Economic Commission for Africa (UNECA, 2009) report also showed that Ethiopia has one of the world's worst crash records with 170 fatalities per 10,000 vehicles. The UNECA (2009) report showed that, despite having a very low road network density and vehicle ownership, the country (Ethiopia) has been cited as the worst example in road crash.

Such unacceptably high road traffic crashes statistics in Addis Ababa are attributed to complex interrelated risk factors ranging from driver and pedestrian behavior, traffic rules and regulations, and vehicle and road conditions. For instance, the Ministry of Infrastructure, Roads Authority (2005) report showed that problems related to the road itself were only responsible for about 1 to $3 \%$ while the largest crashes were attributed to driver error, which accounted for $81 \%$. Similarly, Tesema et al. (2005) in their study of road traffic crashes in Ethiopia, reported that about $81 \%$ of the road traffic crashes countrywide are due to driver errors such as: drivers not respecting pedestrian priority, speeding, unsafe utilization of freight vehicles for passenger transportation, poor driving skills and undisciplined driver behaviour.

Other reports showed that a lack of advanced technology for controlling road crashes in Addis Ababa, a disproportionally low number of traffic police officers per number

Copyright $($ I International Association of African Researchers and Reviewers, 2006-2017: www. afrrevjo.net.

Indexed African Journals Online: www.ajol.info 
of vehicles and roads, bad crossing behaviours of pedestrians, ineffective or nominal road traffic laws and regulations were risk factors of road traffic crashes in Addis Ababa, Ethiopia (e.g., Ministry of Infrastructure, Roads Authority, 2004; Fessaha \& Sileshi, 2014; UNECA, 2009).

\section{The Current Study}

The current research assessed the recent status of the road crashes in the city of Addis Ababa by covering crashes that occurred between the years 2010 and 2014. The study assessed the magnitude of the road crashes and reported the factors contributing to the incidents between the indicated years. These factors contributing to road crashes were registered and reported by traffic police officers. The reported contributing factors were given in terms of respecting traffic rules and regulations, not yielding right of way to pedestrians and vehicles, roads and weather conditions. Driving experiences and other demographic characteristics of the drivers were also reported and assessed. Therefore, the current study is very helpful for policymakers attempting to take intervention measures to reduce the crashes through road safety education and law enforcement, based on up-to-date scientific evidence on the magnitude and contributing factors of road crashes in Addis Ababa.

\section{Methods}

\section{Data Sources and Materials}

Our data source was road traffic crashes in Addis Ababa, Ethiopia, collected by Addis Ababa Police Commission, Traffic Control and Inspection Office, between the years 2010 and 2014. With respect to the quality and validity of the data, there are always differences between government (Addis Ababa Police Commission) and other independent reports. The traffic police reports are most of the time said to be under reporting the incidents (e.g., UNECA, 2009).

\section{Measures}

Addis Ababa Police Commission report of the road crashes were summarized into three levels of injuries (fatal injury, serious injury and minor injury) and property damage.

According to the definitions given by the police commission:

Fatal injury: is any confirmed road crash related death report (either on the spot or any time after the sustained injury) by Minilik II Referral Hospital ${ }^{1}$.

\footnotetext{
${ }^{1}$ Minilik Referral Hospital is one of Federal referral hospitals in Addis Ababa City. The hospital is one of the oldest hospitals built in the country and now provides referral services and road crash related injury case confirmation.
}

Copyright (C) International Association of African Researchers and Reviewers, 2006-2017: www.afrevjo.net.

Indexed African Journals Online: www.ajol.info 
Serious injury: is defined as when one or more road user(s) (pedestrians, passengers and drivers) suffered severe cuts, bleeding, breaks, and other damages which required them to receive medical treatment as an "in-patient" in hospital.

Minor injury: on the other hand, is defined as when one or more road users sustain(s) minor/slight cuts, scratches, and other minor damage which require the road user(s) to be treated as an out-patient without requiring hospitalization, and not resulting in fatality/death.

Property damage: According to the commission, traffic police officers estimate the property damage in terms of financial costs (during the past 5 years roughly 2010-2015 - the exchange rate has been about 1 US $\$=20.00$ Ethiopian currency and this information can also be accessible online).

Generally, the police commission reports of road crashes were a summary all levels of injury and property damage. There was no specific data in terms of number of vehicles and road users involved in particular road crash.

Data analysis

The data received from the Addis Ababa Police Commission were frequency reports of road crashes. Therefore, we first organized the data in accordance with the respective demographic characteristics of road users involved in the crashes; and estimated property damage in terms of financial per year. Then, we organized the data in terms of risk factors for the crashes. However, due to the report was generic and only conveying the summary of frequency of levels of crashes, we could not find how many vehicles and/or road users were involved in any specific crash. Then, after we organized the data, we fed it into the Statistical Package for Social Sciences (SPSS-version 20). Based on the nature of the data, we used basic/descriptive statistics such as frequencies and percentage. We also used tables and graphs to illustrate the results of the data analyses.

\section{Results}

\section{Definitions of injury levels and property damage}

The analysis of the road crash data report from the Addis Ababa Police Commission between 2010 and 2014 showed that 14,263 people sustained different levels of injury, while property damage as a result of the crashes (which did not include costs of injuries for road users) was estimated to be over 19 million US dollars. During the course of the five years, 1,911 were fatal injury reports; 6,932 were serious injury and 5,420 were minor injury reports.

According to our analysis of the report pedestrians were the most affected $(11,305$ or $79 \%$ ) road users, followed by passengers $(2,433$ or $17 \%)$, while crashes on drivers only constituted 529 (or 4\%). In terms of gender, males constituted 10,807 (or 76\%)

Copyright (C) International Association of African Researchers and Reviewers, 2006-2017: www.afrrevjo.net.

Indexed African Journals Online: www.ajol.info 
AFRREV VOL. 11 (2), S/NO 46, APRIL, 2017

compared to females $(3,456$ or $24 \%)$. In terms of injury level, among the 1,911 fatal injuries, 1,501 or $79 \%$ were males compared to 410 or $21 \%$ females; among the 6,932 serious injury reports, 5,255 or $76 \%$ were males compared to 1,677 or $24 \%$ females; and among the 5,420 minor injury reports 4,051 or $75 \%$ were males, compared to 1,369 or $25 \%$ females. An overview of the analysis is provided in Table 1.

Table 1: Demographic characteristics of the victimized road users in Addis Ababa, Ethiopia between the years 2010 and 2014

\begin{tabular}{llrrrr}
\hline & & \multicolumn{4}{c}{ Crashes } \\
\hline \multirow{2}{*}{ Gender } & Fatal injury & \multicolumn{2}{c}{ Serious } & Minor injury & Total \\
& Male & 1,501 & 5,255 & 4,051 & 10,807 \\
Total & Female & 410 & 1,677 & 1,369 & 3,456 \\
& & 1,911 & 6,932 & 5,420 & 14,263 \\
Road & Pedestrians & 1,664 & 5,348 & 4,293 & 11,305 \\
users & Passengers & 179 & 1,326 & 928 & 2,433 \\
Total & Drivers & 68 & 258 & 199 & 525 \\
& & 1,911 & 6,932 & 5,420 & 14,263 \\
\hline
\end{tabular}

Furthermore, our analysis revealed that almost half (46\%) of pedestrians who died, were seriously injured or sustained minor injuries were in the age range between 18 and 30 years followed by those between $31-50$ age range (25\%). Similarly, the analysis showed that $45 \%$ of crashes on passengers involved those aged between 18 and 30 years, while a further $40 \%$ of the crashes on passengers between 31 and 50 years of age.

\section{Risk Factors for Road Crashes in Addis Ababa, Ethiopia}

\section{Demographic Characteristics of Drivers}

The result of the analysis showed that 1,567 (88\%) of fatal injury reports, 4,844 (87\%) of serious injury reports, 4,027 (86\%) of minor injury reports and 43,310 (89\%) of property damage reports were associated with male drivers; compared to 21 (1\%), 329 (6\%), $350(8 \%)$ and 3,833 (8\%) for female drivers respectively.

On the other hand, the analysis, with regard to the age of the drivers, showed that the highest proportion of reported fatal injury (40\%), serious injury (41\%), minor injury $(43 \%)$ and property damage $(41 \%)$ was associated with younger drivers aged between 18-30 years followed by drivers of 31-50 years. An overview of the analysis was presented in Table 2.

Copyright $\odot$ International Association of African Researchers and Reviewers, 2006-2017:

www. afrrevjo.net.

Indexed African Journals Online: www.ajol.info 
AFRREV VOL. 11 (2), S/NO 46, APRIL, 2017

Table 2: Summary of driver age and associated road crashes in Addis Ababa, Ethiopia between the years 2010 and 2014

\begin{tabular}{lllllll}
\hline Drivers' age & & $\begin{array}{c}\text { Fatal } \\
\text { injury }\end{array}$ & $\begin{array}{c}\text { Serious } \\
\text { injury }\end{array}$ & $\begin{array}{c}\text { Minor } \\
\text { injury }\end{array}$ & $\begin{array}{c}\text { Property } \\
\text { damage }\end{array}$ & Total \\
\hline Under 18 & Count & 7 & 100 & 76 & 488 & 671 \\
& Percentage & $0.4 \%$ & $1.8 \%$ & $1.6 \%$ & $1.0 \%$ & $1.1 \%$ \\
\multirow{2}{*}{$18-30$} & Count & 703 & 2,288 & 2,009 & 19,758 & 24,758 \\
& Percentage & $39.6 \%$ & $41.3 \%$ & $42.8 \%$ & $40.6 \%$ & $40.8 \%$ \\
3150 & Count & 661 & 2,061 & 1,673 & 19,709 & 24,104 \\
& Percentage & $37.2 \%$ & $37.2 \%$ & $35.6 \%$ & $40.5 \%$ & $39.7 \%$ \\
& Count & 217 & 721 & 652 & 7,158 & 8,748 \\
& Percentage & $12.2 \%$ & $13.0 \%$ & $13.9 \%$ & $14.7 \%$ & $14.4 \%$ \\
& Count & 189 & 367 & 287 & 1,543 & 2,386 \\
& Percentage & $10.6 \%$ & $6.6 \%$ & $6.1 \%$ & $3.2 \%$ & $3.9 \%$ \\
\hline Total & Count & 1,777 & 5,537 & 4,697 & 48,656 & 60,667 \\
& Percentage & $2.9 \%$ & $9.1 \%$ & $7.7 \%$ & $80.2 \%$ & $99.9 \%$ \\
\hline
\end{tabular}

\section{Driving Experience}

The researchers also analyzed driving experience and reported crash statistics. The analysis showed that the highest proportion of fatal injury reports (796 or 53.3\%) was associated with more experienced drivers (more than 5 years of driving experience), compared to drivers with less than or equal to 5 years of driving experience (698 or $46.7 \%$ of fatal injuries). An overview of the analysis is presented in Table 3.

Table 3: Driving experience and associated road crashes in Addis Ababa, Ethiopia between the years 2010 and 2014

\begin{tabular}{lllllll}
\hline & & & $\begin{array}{c}\text { Fatal } \\
\text { injury }\end{array}$ & $\begin{array}{c}\text { Serious } \\
\text { injury }\end{array}$ & $\begin{array}{l}\text { Minor } \\
\text { injury }\end{array}$ & Total \\
\hline Experiences & $\begin{array}{l}\text { Less than } \\
\text { or equal } \\
\text { to 5 }\end{array}$ & Count & 698 & 2,487 & 2,229 & 5,414 \\
& Percentage & $46.7 \%$ & $49.3 \%$ & $51.7 \%$ & $49.9 \%$ \\
& $\begin{array}{lllll}\text { years } \\
\text { Greater } \\
\text { than 5 }\end{array}$ & Count & 796 & 2,561 & 2,080 & 5,437 \\
& Percentage & $53.3 \%$ & $50.7 \%$ & $48.3 \%$ & $50.1 \%$ \\
& & & & & \\
\hline Tears & & Count & 1,494 & 5,048 & 4,309 & 10,851 \\
& & Percentage & $13.8 \%$ & $46.5 \%$ & $39.7 \%$ & $100.0 \%$ \\
\hline
\end{tabular}

Copyright (C) International Association of African Researchers and Reviewers, 2006-2017:

$$
\text { www.afrevjo.net. }
$$

Indexed African Journals Online: www.ajol.info 
AFRREV VOL. 11 (2), S/NO 46, APRIL, 2017

\section{Driving Behaviors}

Finally, the researchers also analyzed driving behaviours related to road crash reports in terms of drivers' not yielding right of way to pedestrians and other vehicles, respecting traffic lights and signs and other related traffic rules. The analysis showed that drivers' not yielding right of way to pedestrians was associated with the highest proportion of fatal injury (76\%), serious injury (69\%) and minor injury reports (65\%), while drivers' not yielding right of way to other vehicles was reported as the largest contributing factor toward property damage (accounting for about $26 \%$ of property damage) followed by tailgating/not keeping distance, which accounted for about $20 \%$ of property damage. An overview of the analysis is presented in Table 4.

Table 4: Reported contributing factors to road traffic crashes in Addis Ababa, Ethiopia between the years 2010 and 2014

\begin{tabular}{|c|c|c|c|c|c|c|}
\hline \multicolumn{2}{|c|}{ Reported Contributing factors } & \multirow{2}{*}{$\begin{array}{r}\begin{array}{l}\text { Fatal } \\
\text { injury }\end{array} \\
1,350\end{array}$} & \multirow{2}{*}{\begin{tabular}{|l|}
$\begin{array}{l}\text { Serious } \\
\text { injury }\end{array}$ \\
3,803 \\
\end{tabular}} & \multirow{2}{*}{$\begin{array}{l}\begin{array}{l}\text { Minor } \\
\text { injury }\end{array} \\
3,032\end{array}$} & \multirow{2}{*}{\begin{tabular}{|l|}
$\begin{array}{l}\text { Property } \\
\text { damage }\end{array}$ \\
3,462
\end{tabular}} & \multirow{2}{*}{\begin{tabular}{|l} 
Total \\
11,647
\end{tabular}} \\
\hline Not yielding right & Count & & & & & \\
\hline $\begin{array}{l}\text { of way to } \\
\text { pedestrians }\end{array}$ & Percentage & $76.0 \%$ & $69.0 \%$ & $64.8 \%$ & $7.1 \%$ & $19.2 \%$ \\
\hline Unknown cause & Count & 92 & 172 & 137 & 750 & 1,151 \\
\hline $\begin{array}{l}\text { (not registered due } \\
\text { to runaway) }\end{array}$ & Percentage & $5.2 \%$ & $3.1 \%$ & $2.9 \%$ & $1.5 \%$ & $1.9 \%$ \\
\hline Not keeping & Count & 63 & 235 & 156 & 9,523 & 9,977 \\
\hline distance/tailgating & Percentage & $3.5 \%$ & $4.3 \%$ & $3.3 \%$ & $19.6 \%$ & $16.5 \%$ \\
\hline Not keeping right & Count & 57 & 172 & 177 & 6,334 & 6,740 \\
\hline hand side & Percentage & $3.2 \%$ & $3.1 \%$ & $3.8 \%$ & $13.0 \%$ & $11.1 \%$ \\
\hline Inappropriate/wrong & Count & 35 & 105 & 131 & 3,410 & 3,681 \\
\hline turn & Percentage & $2.0 \%$ & $1.9 \%$ & $2.8 \%$ & $7.0 \%$ & $6.1 \%$ \\
\hline Automatic/sudden & Count & 33 & 37 & 75 & 908 & 1,053 \\
\hline $\begin{array}{l}\text { driving from where } \\
\text { it stopped }\end{array}$ & Percentage & $1.9 \%$ & $0.7 \%$ & $1.6 \%$ & $1.9 \%$ & $1.7 \%$ \\
\hline Driving beyond & Count & 27 & 87 & 75 & 1,936 & 2,125 \\
\hline speed limit & Percentage & $1.5 \%$ & $1.6 \%$ & $1.6 \%$ & $4.0 \%$ & $3.5 \%$ \\
\hline Not yielding right & Count & 23 & 446 & 499 & 12,469 & 13,437 \\
\hline $\begin{array}{l}\text { of way to other } \\
\text { vehicles }\end{array}$ & Percentage & $1.3 \%$ & $8.1 \%$ & $10.7 \%$ & $25.6 \%$ & $22.2 \%$ \\
\hline Problems related to & Count & 21 & 16 & 19 & 253 & 309 \\
\hline vehicles & Percentage & $1.2 \%$ & $0.3 \%$ & $0.4 \%$ & $0.5 \%$ & $0.5 \%$ \\
\hline Other Contributing & Count & 20 & 56 & 42 & 523 & 641 \\
\hline $\begin{array}{l}\text { factors } \\
\text { (Contributing } \\
\text { factors not listed in } \\
\text { this checklist) }\end{array}$ & Percentage & $1.1 \%$ & $1.0 \%$ & $0.9 \%$ & $1.1 \%$ & $1.1 \%$ \\
\hline Inappropriate/illegal & Count & 19 & 62 & 71 & 3,042 & 3,194 \\
\hline overtaking & Percentage & $1.1 \%$ & $1.1 \%$ & $1.5 \%$ & $6.3 \%$ & $5.3 \%$ \\
\hline Inappropriate/illegal & Count & 12 & 39 & 28 & 316 & 395 \\
\hline occupancy & Percentage & $0.7 \%$ & $0.7 \%$ & $0.6 \%$ & $0.6 \%$ & $0.7 \%$ \\
\hline
\end{tabular}

Copyright (C) International Association of African Researchers and Reviewers, 2006-2017: www.afrevjo.net.

Indexed African Journals Online: www.ajol.info 


\begin{tabular}{lllllll} 
Pedestrians' & Count & 7 & 52 & 46 & 58 & 163 \\
problem & Percentage & $0.4 \%$ & $0.9 \%$ & $1.0 \%$ & $0.1 \%$ & $0.3 \%$ \\
Overtaking on curve & Count & 6 & 45 & 33 & 429 & 513 \\
& Percentage & $0.3 \%$ & $0.8 \%$ & $0.7 \%$ & $0.9 \%$ & $0.8 \%$ \\
Inappropriate & Count & 5 & 7 & 10 & 186 & 208 \\
stopping & Percentage & $0.3 \%$ & $0.1 \%$ & $0.2 \%$ & $0.4 \%$ & $0.3 \%$ \\
Automatic/sudden & Count & 3 & 41 & 33 & 881 & 958 \\
turning after & Percentage & $0.2 \%$ & $0.7 \%$ & $0.7 \%$ & $1.8 \%$ & $1.6 \%$ \\
overtaking & & & & & & \\
Violating 'GIVE & Count & 2 & 30 & 44 & 533 & 609 \\
PRIORITY' sign & Percentage & $0.1 \%$ & $0.5 \%$ & $0.9 \%$ & $1.1 \%$ & $1.0 \%$ \\
Violating 'STOP' & Count & 1 & 7 & 10 & 314 & 332 \\
sign & Percentage & $0.1 \%$ & $0.1 \%$ & $0.2 \%$ & $0.6 \%$ & $0.5 \%$ \\
Violating traffic & Count & 1 & 2 & 1 & 262 & 266 \\
police order & Percentage & $0.1 \%$ & $0.0 \%$ & $0.0 \%$ & $0.5 \%$ & $0.4 \%$ \\
Drug abuse & Count & 0 & 18 & 16 & 967 & 1001 \\
& Percentage & $0.0 \%$ & $0.3 \%$ & $0.3 \%$ & $2.0 \%$ & $1.7 \%$ \\
Violating traffic & Count & 0 & 16 & 5 & 227 & 248 \\
lights & Percentage & $0.0 \%$ & $0.3 \%$ & $0.1 \%$ & $0.5 \%$ & $0.4 \%$ \\
Distracted driving & Count & 0 & 4 & 3 & 116 & 123 \\
& Percentage & $0.0 \%$ & $0.1 \%$ & $0.1 \%$ & $0.2 \%$ & $0.2 \%$ \\
Inappropriate & Count & 0 & 3 & 4 & 67 & 74 \\
lighting & Percentage & $0.0 \%$ & $0.1 \%$ & $0.1 \%$ & $0.1 \%$ & $0.1 \%$ \\
Driving with & Count & 0 & 2 & 6 & 66 & 74 \\
fatigue/sleepy & Percentage & $0.0 \%$ & $0.0 \%$ & $0.1 \%$ & $0.1 \%$ & $0.1 \%$ \\
Problems related to & Count & 0 & 0 & 0 & 34 & 34 \\
road & Percentage & $0.0 \%$ & $0.0 \%$ & $0.0 \%$ & $0.1 \%$ & $0.1 \%$ \\
Total & Count & 1,777 & 5,537 & 4,697 & 48,656 & 60,667 \\
& Percentage & $2.9 \%$ & $9.1 \%$ & $7.7 \%$ & $80.2 \%$ & $99.9 \%$ \\
\hline
\end{tabular}

\section{Road Conditions}

The researchers also analyzed the road conditions relating to the crashes. According to their analysis, over $83 \%$ of crashes resulting in fatal injury, $87 \%$ resulting in serious injury, $83 \%$ resulting in minor injury and $82 \%$ of property damage reports occurred on straight roads; whereas about $5 \%$ of fatal injury, $4 \%$ serious injury, $6 \%$ of minor injury and $4 \%$ of property damage reports occurred on downward-sloping roads. Additionally, the researchers also analyzed reported asphalt pavement conditions and respective reported road crashes. The analysis showed that over $90 \%$ of fatal injury, serious injury, minor injury and property damage reports occurred on good asphalt pavements, and dry roads.

\section{Weather Conditions}

The analysis of weather conditions and associated crashes showed that over $80 \%$ of fatal injury, serious injury, minor injury and property damage reports occurred during good weather conditions. In terms of light condition, the analysis showed that over $65 \%$

Copyright (C) International Association of African Researchers and Reviewers, 2006-2017:

$$
\text { www.afrevjo.net. }
$$

Indexed African Journals Online: www.ajol.info 
of fatal injury, $68 \%$ of serious injury, $64 \%$ of minor injury and $70 \%$ of property damage reports occurred during daylight; whereas $18 \%$ of fatal injury, $15 \%$ of serious injury, $16 \%$ of minor injury and $14 \%$ of property damage reports were registered following crashes that occurred after dark in good road lighting conditions.

\section{Discussion}

Road traffic crashes have become a major public health concern and economic burden claiming thousands of lives, resulting in thousands of physical injuries and costing the economy millions of dollars between 2010 and 2014 .

The current study showed that most of the people affected by the road crashes were pedestrians, passengers and of male gender. In this regard, other research has already documented that being a pedestrian, male, and of young age is highly correlated with a higher risk of road fatality (e.g., Damen, 2014; Guyu, 2013; Odero, Khayesi, \& Heda, 2010; Vorko-Jović, Kern, \& Biloglav, 2006; Yan, Radwan, \& Abdel-Aty, 2005).

With respect to the risk factors for road crashes in Addis Ababa, Ethiopia, the research findings also showed that most of the crashes were associated with drivers' errors and demographic characteristics. Most pedestrian fatalities and physical injuries were due to drivers' not yielding right of way to pedestrians. In line with this finding, studies conducted on road traffic crashes in Ethiopia showed that over $81 \%$ of road crashes were a result of driver error, such as failure to give priority for pedestrians (drivers' not yielding right of way to pedestrians) (Damen, 2014; Fesseha \& Sileshi, 2014; Guyu, 2013; Tesema et al., 2005). Other studies conducted in a different context showed that being of male gender, young age and also of a poorly educated or uneducated background are related to a higher risk of being involved in road traffic crashes (e.g., Zang, Yau, \& Chen, 2013). Likewise, the study findings on risk factors contributing to fast-developing countries [in the case of Qatar] by Burgut, Bener, Sidahmed, Albuz, Sanya and Ali Khan (2010) revealed that among the socio-demographic factors, male drivers and young drivers aged 25-34 years were found to have a higher accident involvement.

The researchers also revealed in their analysis results that a higher number of crashes occurred with good road conditions, good asphalt pavements and good lighting (daylight). This finding is slightly congruent with what Chan, Huang, Yan, and Richards (2010) found out (for Tennessee, Nashville city, United States) concerning pavement maintenance [good road pavement] being essential for ensuring good riding quality and the avoidance of traffic congestion, air pollution and accidents. Similarly, Burgut, Bener, Sidahmed, Albuz, Sanya, and Ali Khan (2010) revealed that most of the crashes in Qatar happened during sunny days (84.7\%). However, there are contrasting findings - especially on asphalt pavement conditions and road crashes - as the research results of Li, Liu and Ding (2013) suggested that poor pavement condition were associated with proportionally more severe crashes, but very poor pavement conditions

Copyright (C) International Association of African Researchers and Reviewers, 2006-2017: www.afrevjo.net.

Indexed African Journals Online: www.ajol.info 
were actually associated with less severe crashes. Meanwhile, very good pavement conditions might induce speeding behaviors and therefore could be the cause of more severe crashes, especially on non-freeway arterials and during favorable driving conditions.

Overall, the results of this current study suggest that among the other assessed risk factors including road conditions, asphalt pavement conditions, light conditions, and traffic rules and regulations, most of the road crashes in Addis Ababa were clearly associated with drivers' not yielding right of way to pedestrians for crashes on pedestrians, and drivers' not yielding right of way to other vehicles for property damage. Therefore, law enforcers, road authority, drivers' training and licensing organizations and other stakeholders need to give due attention to such driving behavior in order to reduce road crashes in the city and thereby save the lives, physical injuries and economic losses of the citizens. It is also important in future to take into account studies ultimately the road traffic system as a whole must be considered (see also, system approaches, e.g., Bliss and Breen, 2008; Special Issue Traffic Injury Analysis and Prevention, 2015); the combination and interaction of all factors ultimately determine the level of safety. For example, the fact that most crashes happen on paved roads does not automatically mean that this is an irrelevant factor. The safest roads are those that automatically induce safe behavior. Certain roads can for example still induce unsafe behavior, such as driving at too high a speed or not giving way to pedestrians in those situations where pedestrians and other vulnerable road users are present, but are not anticipated by other road users due to the layout of the road layout.

\section{References}

Bliss, T. (2004). Implementing the recommendations of the world report on road traffic injury prevention. No. TN-1.

Burgut, H. R., Abdulbari Bener, H. S., Rama Albuz, R. S., \& Waleed, A. K. (2010). Risk factors contributing to road traffic crashes in a fast-developing country: The neglected health problem. Ulus Travma Acil Cerrahi Derg 16, no. 6 (2010): 497-502.

Chan, C. Y., Baoshan, H., Xuedong, Y., \& Stephen, R. (2010). Investigating effects of asphalt pavement conditions on traffic accidents in Tennessee based on the pavement management system (PMS). Journal of advanced transportation 44, no. 3 (2010): 150-161.

Daie, G. F., \& Tebarek, L. M. (2013). Identifying major urban road traffic accident black-spots (RTABSs): A sub-city based analysis of evidences from the city of Addis Ababa, Ethiopia. Journal of Sustainable Development in Africa 15, no. 2 .

Copyright (C) International Association of African Researchers and Reviewers, 2006-2017: www.afrevjo.net.

Indexed African Journals Online: www.ajol.info 
AFRREV VOL. 11 (2), S/NO 46, APRIL, 2017

Deckert, C. (2016). Nachhaltige logistik. In CSR und Logistik, pp. 3-41. Heidelberg: Springer Berlin.

Hassen, A., Godesso, A., Abebe, L., \& Girma, E. (2011). Risky driving behaviors for road traffic accident among drivers in Mekele city, Northern Ethiopia. BMC research notes 4, no. 1 (2011): 535.

Kopits, E., \& Cropper, M. (2003). Traffic fatalities and economic growth.

Lagarde, E. (2007). Road traffic injury is an escalating burden in Africa and deserves proportionate research efforts. PLoS Med 4, no. 6 (2007): 170.

Li, Y., Liu, C. \& Ding, L. (2013). Impact of pavement conditions on crash severity. Accident Analysis \& Prevention 59 (2013): 399-406.

Mekonnen, F. H., \& Teshager, S. (2014). Road traffic accident: the neglected health problem in Amhara National Regional State, Ethiopia. Ethiopian Journal of Health Development 28, no. 1 (2014): 3-10.

Ministry of Infrastructure, Roads Authority (2004). Road Safety Audit Manual. Addis Ababa, Ethiopia.

Nantulya, V. M., \& Reich, M. R. (2002). The neglected epidemic: road traffic injuries in developing countries. BMJ: British Medical Journal 324, no. 7346 (2002): 1139.

Odero, W., Khayesi, M. \& Heda, P. M. (2003). Road traffic injuries in Kenya: Magnitude, causes and status of intervention. Injury Control and Safety Promotion 10, no. 1-2 (2003): 53-61.

Pucher, J., \& Dijkstra, L. (2003). Promoting safe walking and cycling to improve public health: lessons from the Netherlands and Germany. American Journal of Public Health 93, no. 9 (2003): 1509-1516.

Tesema, T. B., Abraham, A. \& Grosan, C. (2005). Rule mining and classification of road traffic accidents using adaptive regression trees." International Journal of Simulation 6, no. 10-11 (2005): 80-94.

The Economist (24 October 2015). Road deaths in Africa Worse than malaria.

United Nations Economic Commission for Africa (2009). Case study: Road safety in Ethiopia. Addis Ababa, Ethiopia.

Vorko-Jović, A., Kern, J. \& Biloglav, Z. (2006). Risk factors in urban road traffic accidents. Journal of Safety Research 37, no. 1 (2006): 93-98.

Copyright (c) International Association of African Researchers and Reviewers, 2006-2017:

www.afrrevjo.net.

Indexed African Journals Online: www.ajol.info 
Yan, X., Radwan, E., \& Abdel-Aty, M. (2005). Characteristics of rear-end accidents at signalized intersections using multiple logistic regression model. Accident Analysis \& Prevention 37, no. 6 (2005): 983-995.

Zhang, G., Yau, K. K. \& Chen, G. (2013). Risk factors associated with traffic violations and accident severity in China. Accident Analysis \& Prevention 59 (2013): 1825.

\section{Appendices \\ Interview Guide}

General Direction: Dear officer, we, a team of researchers, wanted to investigate the risk factors and other related issues of road crashes in Addis Ababa, Ethiopia between the years 2010-2014. So, we wanted to get additional data from you, in addition to what we have obtained from the statistics department. All of the information you give us will be treated confidentially and only used for the purpose of the research. We would like to thank you in advance for your cooperation!

\section{Questions for interview}

1. Who is responsible for recording and reporting road crashes committed in Addis Ababa city?

2. How are the levels of crashes defined? (hint: different countries have different definitions for the types/levels of road crashes such as:

a) Fatal injury

b) Serious injury

c) Minor injury and

d) Property damage. Therefore, how are these levels/types of crashes defined in the context of Addis Ababa city?

3. Is there any additional information you would like to give us for the purpose of this study?

Thank you once again for your cooperation, the research team!

Copyright (C) International Association of African Researchers and Reviewers, 2006-2017:

$$
\text { www. afrrevjo.net. }
$$

